\title{
Adequacy of the Simplified Version of the Tinnitus Handicap Inventory (THI-S) to Measure Tinnitus Handicap and Relevant Distress
}

\author{
Jae Hee Lee ${ }^{1}$, Jin-Ju Ra ${ }^{1,2}$, and Young Ho Kim² \\ 1 Department of Audiology, Hallym University of Graduate Studies, Seoul, \\ ${ }^{2}$ Department of Otolaryngology-Head and Neck Surgery, Boramae Medical Center, Seoul, Korea
}

Received February 18, 2014

Revised March 15, 2014

Accepted March 20, 2014

\author{
Address for correspondence \\ Jae Hee Lee, PhD \\ Department of Audiology, \\ Hallym University \\ of Graduate Studies, \\ 405 Yeoksam-ro, Gangnam-gu, \\ Seoul 135-841, Korea \\ Tel +82-2-2051-2942 \\ Fax +82-2-3453-6618 \\ E-mail1eejaehee@hallym.ac.kr
}

Background and Objectives: The Tinnitus Handicap Inventory (THI) often requires patients to devote their time to complete the questionnaire than they expect. Given that it limits the effectiveness of THI in a busy clinical practice that desires a quick and easy assessment of tinnitus handicap, this study evaluated clinical usefulness of a Simplified version of Tinnitus Handicap Inventory (THI-S) in measuring the severity of tinnitus handicap as well as predicting the psychological distress associated with tinnitus. Subjects and Methods: A total of 129 outpatients suffering from tinnitus (61 with normal hearing and 68 with hearing loss) participated in this study. The responses of THI-S (10 items) and THI (25 items) were evaluated to quantify the subjective handicap of tinnitus. The self-perceived level of stress, anxiety, and depression of all participants was measured with a series of self-report questionnaires such as Korean version of Brief Encounter Psychosocial Instrument (BEPSI), State Trait Anxiety Inventory (STAI), and Beck Depression Inventory (BDI), respectively. All the questionnaire responses were analyzed using non-parametric analyses to examine the convergence, comparability, internal consistency reliability and validity of THI-S. Results: The severity of tinnitus handicap and the relevant psychological distress greatly varied across individuals. The THI-S responses were comparable to original THI responses, regardless of hearing status of patients. The internal consistency of THI-S responses was found to be good for total score (Cronbach's $\alpha=0.83-$ 0.91), with moderately high consistency for the emotional, functional, and catastrophic subscales. Significant $(p<0.01)$ correlations of the THI-S with the THI $\left(r_{s}=0.95\right)$ as well as with the BEPSI, STAI, BDI questionnaires $\left(r_{s}=0.40-0.45\right)$ suggest that the THI-S questionnaire appeared to be useful to provide objective data of subjective tinnitus handicap as well as predict psychological distress. Three factors were extracted through factor analysis, which explained $73 \%$ of the total variance. Conclusions: Despite reducing the length of 25 items of THI to 10 items, the THI-S can be used as s a simple but reliable and valid tool for evaluating severity of tinnitus handicap as well as detecting its negative impact on psychological functioning.

Korean J Audiol 2014;18(1):19-27

KEY WORDS: THI-S · THI · Tinnitus handicap.

\section{Introduction}

Tinnitus is the experience of hearing a sound without any relevant external stimulation. Tinnitus is a chronic condition

This is an Open Access article distributed under the terms of the Creative Commons Attribution Non-Commercial License (http://creativecommons. org/licenses/by-nc/3.0/) which permits unrestricted non-commercial use, distribution, and reproduction in any medium, provided the original work is properly cited. affecting 15 to $30 \%$ of adult population. ${ }^{1)}$ The prevalence of tinnitus is known to increase with age. Although tinnitus can be managed with several ways, there is no specific cure for tinnitus. ${ }^{2)}$ Tinnitus can affect a person's everyday activities, mental and physical functioning, which can lead to lack of concentration, deteriorated quality of life. ${ }^{3)}$ The extent of sufferings from tinnitus greatly vary across individuals, ${ }^{4)}$ frequently associated with personality, ${ }^{5,6)}$ tinnitus copying styles, ${ }^{7)}$ and 
self-focused somatic attention. ${ }^{8)}$

Although there is no universally accepted scale for diagnosis and assessment of tinnitus, the tinnitus-related disability is usually quantified by structured self-report questionnaires. ${ }^{9)}$ Given the subjective nature of tinnitus, numerous subjective questionnaires have been developed to measure the severity of tinnitus. One of the most commonly used measures to identify tinnitus handicap is Tinnitus Handicap Inventory (THI) ${ }^{10)}$ There are two versions of THI questionnaires (45-item alpha version and 25-item beta version), and the 25-item THI has been more commonly used for the clinical purpose. However, responding to all the 25 items of THI questionnaire may be often deterrent in a busy clinical practice for patients with tinnitus. Considering this, Newman, et al. ${ }^{11)}$ has developed a screening version of the THI in English, called THI-S. The investigators determined that the THI and THI-S responses were highly comparable $(r=0.90)$ and that THI-S showed good test-retest reliability $(r=0.81)$, concluding that THI-S is a psychometrically robust screening measure of tinnitus handicap. In German, a 12-item tinnitus handicap inventory (THI-12) was also developed and its good reliability and validity was confirmed. ${ }^{9,12)}$

In Korea, Mun, et al. ${ }^{13)}$ have now proposed a short form of THI, called THI-S (a simplified version of Korean adaptation Tinnitus Handicap Inventory), with exploring which items of THI would be the best to be included as an abbreviated form. The THI-S includes 10 items out of the original 25-item THI questions, which is similar to the screening version of THI in English. ${ }^{11)}$ With 100 patients with tinnitus, Mun, et al. determined that the THI and THI-S have an excellent comparability. Because of simplicity, 10-item THI-S requires fewer demands and less time of patients than 25-item THI such that the THI-S may be more useful and easily applicable in a busy clinical setting. In order to use THI-S as a reliable and valid measure of tinnitus-related disability, then the THI-S should be enough to assess the severity of tinnitus as well as reflect distress such as anxiety, depression, and stress of tinnitus sufferers. This should not be focused on only the tinnitus patients with normal hearing. Rather, this finding should be also generalized to the tinnitus patients with hearing loss. To prove this, the present study attempted to answer the specific research questions as follows. First, are the THI-S responses comparable with THI responses, regardless of patients' hearing status? Second, are THI-S responses useful to predict tinnitus-related distress for both normal-hearing and hearing-impaired tinnitus patients? Third, does 10-item THI-S questionnaire have a good internal reliability and validity?

\section{Subjects and Methods}

\section{Subjects}

A total of 129 patients (63 male, 66 female) ranging in age from 16 to 74 years (mean age $=48$ years) participated in this study. The subject sample was drawn from outpatients with a primary complaint of tinnitus who visited the Otolaryngology, Head and Neck Surgery, Boramae Medical Center, from April 2013 to October 2013. All the participants agreed on research participation. Patients were excluded if they had neurologic diseases or a history of vertigo/dizziness or if they could not fill in the subjective questionnaires completely.

Psychoacoustic pitch and loudness matches of tinnitus as well as hearing thresholds were measured through clinical audiometer and earphones (Audiometer: Aurical plus, GN Otometrics, Taastrup, Denmark; Headphone: TDH 39, Telephonics, New York, USA). Table 1 displays the tinnitus characteristics of 129 participants. Among 129 patients, 99 participants had unilateral tinnitus (37 at right ear and 62 at left ear) and 30 participants had bilateral tinnitus. The mean loudness of tinnitus was $60.91 \mathrm{~dB}$ HL (range from 15 to $100 \mathrm{~dB} \mathrm{HL}$ ) and the pitch of tinnitus was $6386 \mathrm{~Hz}$ (ranged from $500 \mathrm{~Hz}$ to 8000 $\mathrm{Hz}$ ). The average duration of tinnitus was 20 months (from 1 month to 30 year). Subjects reported various types of sounds as tinnitus such that the sound perceived by 95 patients $(73.6 \%)$ was pure tone, narrow band noise for 13 listeners (10.1\%), pulsing for 5 listeners (3.9\%), white noise for 5 listeners (3.9\%), warble tone for one listener $(0.8 \%)$, and unknown sound for 10 listeners $(7.8 \%)$.

Among 129 subjects, 61 participants had normal hearing and 68 participants had mild to moderate hearing loss. For tinnitus only (without hearing loss) listeners, the hearing thresholds at frequencies from 250 to $4000 \mathrm{~Hz}$ at octave scale were less than $15 \mathrm{~dB}$ HL for both ears. Their word recognition score was $100 \%$ for both ears. For listeners with both tinnitus and

Table 1. Tinnitus characteristics of patients $(n=129)$

\begin{tabular}{lrc}
\hline & No. & $\%$ \\
\hline Tinnitus ear & 37 & 28.7 \\
Right ear & 62 & 48.1 \\
Left ear & 30 & 23.3 \\
Bilateral & & \\
Type of tinnitus sound & 95 & 73.6 \\
Pure tone & 1 & 0.8 \\
Warble tone & 13 & 10.1 \\
Narrow band noise & 5 & 3.9 \\
Pulsing & 5 & 3.9 \\
White noise & 10 & 7.8 \\
Unknown & &
\end{tabular}


hearing loss, the puretone threshold average across frequencies of 500, 1000, 2000, $4000 \mathrm{~Hz}$ of ( $\mathrm{n}=61)$ was 28.43 and $32.48 \mathrm{~dB}$ HL for right and left ear. The hearing thresholds of right ear were 17.13 [standard deviation $(\mathrm{SD})=9.9$ ], $17.13(\mathrm{SD}$ $=10.3), 22.05(\mathrm{SD}=11.1), 23.53(\mathrm{SD}=13.6), 39.7(\mathrm{SD}=20.5)$, and $57.1 \mathrm{~dB}$ HL $(\mathrm{SD}=22.1)$ from 250 to $8000 \mathrm{~Hz}$ at octave scale, and the hearing thresholds of left ear were 18.38 (SD= 13), 18.68 ( $\mathrm{SD}=12.7), 22.65(\mathrm{SD}=13.1), 28.53(\mathrm{SD}=15.2)$, $46.25(\mathrm{SD}=19.4)$, and $58.68 \mathrm{~dB} \mathrm{HL}(\mathrm{SD}=19.3)$ at the same frequency scales. The averaged word recognition score for participants with tinnitus and hearing loss was greater than $96.6 \%$ and $94.8 \%$ for right and left ear, respectively.

\section{Subjective questionnaires}

In order to assess the influence of tinnitus on daily life, all participants were asked to complete a series of subjective questionnaires for evaluating the severity of tinnitus handicap, stress, anxiety, and depression, respectively. The details of each questionnaire are listed below in order.

\section{THI and THI-S (original and simplified version of Tinnitus Handicap Inventory)}

The tinnitus handicap was evaluated with 25-item THI questionnaire. As described above, THI is a widely used questionnaire to assess the severity of tinnitus. A Korean adaptation of $\mathrm{THI}^{14)}$ is composed of 25 items in total, with functional (11 items), emotional (9 items), and catastrophic (5 items) subscales. Three response options $(0=$ none, $2=$ sometimes, $4=$ always) are available for each item, and the total score is calculated by summing all responses. A total possible score of THI ranges from 0 to 100, and the higher score of THI represents greater handicap from tinnitus. The THI score of $0-16$ means "no or slight handicap", 18 to 36 indicates "mild", 38 to 56 indicates "moderate", 58 to 76 indicates "severe", and a score of 78-100 is classified as "catastrophic handicap".

Mun, et al. ${ }^{13)}$ recently developed a Simplified version of THI (THI-S) by selecting 10 items out of 25 items of THI on the basis of THI responses by 100 tinnitus patients. Parallel to the THI, the 10 questions of THI-S consist of three subscales comprising 4 emotional items (E10, E16, E21, E22 items in THI), 4 functional items (F1, F12, F18, F20 items in THI), and 2 catastrophic items (C8, C23 items in THI). Since the THI-S uses the identical scoring method of THI, a total possible score of THI-S ranges from 0 to 40 . The higher the score, the more handicap they have due to tinnitus.

\section{Brief Encounter Psychosocial Instrument (BEPSI)}

The degree of stress was assessed using a Korean version Brief Encounter Psychosocial Instrument (BEPSI). ${ }^{15)}$ The origi- nal questionnaire of BEPSI was developed in $1988,{ }^{16)}$ which is designed to reflect external demand, internal demand, differences in external and internal demand, uncertainty of demand, and combinations of demands. The BEPSI was translated into Korean ${ }^{17)}$ and modified to have a good reliability and validity. ${ }^{15)}$ The Korean version BEPSI is a 5-item self-report questionnaire, each of which is answered using a 5-point Likert scale. Scores of each of the 5 questions are summed up and divided by 5 as a final score. The total score of less than 1.3 represents "low stress", 1.3 to 2.3 as "moderate stress", and 2.4 or higher defined as "severe stress".

\section{State Trait Anxiety Inventory (STAI)}

Individual status of state and trait anxiety was examined with a Korean version of State Trait Anxiety Inventory (STAI) questionnaire. Spielberger, et al. ${ }^{18)}$ developed the STAI questionnaire, consisting of two 20-item questions (40 items in total). The Korean version of STAI was proposed and the investigators reported its good reliability and validity. ${ }^{19)}$ Each of the STAI 1 and 2 includes 20 items that are rated on a 4-point Likert scale (1 to 4), with a total possible score ranging from 20 to 80 . The STAI 1 (state) evaluates the current state of anxiety whereas the STAI 2 (trait) shows relatively general feeling of respondents such as calmness, confidence, and security. In STAI 1, a score of $\leq 52$ indicates "normal", 53 to 56 as "mild", 57 to 61 as "moderate", and $\geq 62$ as "severe anxiety". In STAI 2, a score of $\leq 54$ is classified as "normal", 55 to 58 as "mild", 59 to 63 as "moderate", and $\geq 64$ as "severe anxiety".

\section{Beck Depression Inventory (BDI)}

Depressive symptom was measured by a Korean version of the Beck Depression Inventory (BDI). The original BDI was developed to measure the type as well as the degree of depression based on the depressive symptoms. ${ }^{20)}$ The standardization of BDI was conducted in Korean, ${ }^{21)}$ and its good reliability and validity has been also reported in other studies. ${ }^{22,23)}$ This inventory has 21 items and each item is rated on a 4-point Likert scale (0 to 3), with a total possible score ranging from 0 to 63 . The BDI score of $\leq 9$ is defined as "normal", 10 to 15 as "mild", 16 to 23 as "moderate", and 24 to 63 as "severe degree of depression".

\section{Statistical analysis}

Statistical analyses were conducted by the Statistical Package for the Social Sciences version 18.0 for Windows software package (SPSS Inc., Chicago, IL, USA). All the questionnaire responses were analyzed using non-parametric analyses (MannWhitney test for group comparison, Spearman's rank-order correlation for the relationship among responses). A $p$ value of 
less than 0.01 was considered to be statistically significant. The Cronbach's coefficient $\alpha$ was calculated to evaluate the internal consistency of the THI-S and THI questionnaires (where $\alpha$ value $>0.7$ suggests a satisfactory internal consistency ${ }^{24)}$ ). A principal component factor analysis with varimax rotation was conducted to verify the factor structure of THIS. For this, a three-factor extraction solution was applied, with the factor-loading criterion greater than 0.5 .

\section{Results}

\section{Mean and distribution of scores}

Table 2 shows the mean scores of THI-S, THI, BEPSI, STAI 1, STAI 2, and BDI questionnaires for tinnitus patients with or without hearing loss (HL). The mean total score of THI-S was $11.84(\mathrm{SD}=8.31)$ and $13.69(\mathrm{SD}=11.66)$ for tinnitus only $(\mathrm{n}=61)$ and tinnitus and HL participants $(n=68)$. Their mean THI score was $30.36(\mathrm{SD}=19.43)$ and $32.41(\mathrm{SD}=25.95)$, respectively. An extremely high individual variability was found in both THI-S and THI scores (Table 2), given the possible range of score for THI-S ( 0 to 40 ) and THI (0 to 100). The mean score of BEPSI, STAI 1, STAI 2, and BDI questionnaire was 1.98 $(\mathrm{SD}=0.76), 47.20(\mathrm{SD}=10.73), 47.10(\mathrm{SD}=9.8)$, and 12.61 $(\mathrm{SD}=8.98)$ for tinnitus only patients, whereas the average score of the same questionnaires was $1.74(\mathrm{SD}=0.58), 43.53(\mathrm{SD}=$ 9.69), 43.93 ( $\mathrm{SD}=9.85)$, and $11.03(\mathrm{SD}=8.16)$ for tinnitus and HL patients. Like the scores of tinnitus handicap, a large individual variability was also found in the BEPSI, STAI 1, STAI 2, BDI scores.

Table 3 displays distribution of 129 patients according to severity classification of tinnitus handicap, stress, anxiety, and depression. Since there is no definition of classification for THI-S yet, the THI-S scores could not be displayed according to the severity categorization. As in distribution of the THI score, $67-70 \%$ of the tinnitus patients in this study had no or mild handicap of tinnitus, whereas approximately 10-20\% of patients fell into severe to catastrophic handicap groups, regardless of presence of hearing loss. Most of patients ( $>95 \%$ ),

Table 2. Mean scores and range of THI-S, THI, BEPSI, STAI 1, STAI 2, and BDI questionnaires for tinnitus listeners with or without hearing loss

\begin{tabular}{|c|c|c|c|c|c|c|c|}
\hline & & THI-S & THI & BEPSI & STAI 1 & STAI 2 & $\mathrm{BDI}$ \\
\hline \multirow[t]{2}{*}{ Tinnitus only $(n=61)$} & Mean & 11.84 & 30.36 & 1.98 & 47.20 & 47.10 & 12.61 \\
\hline & Range & $0-40$ & $0-98$ & $1-4$ & $21-73$ & $24-74$ & $0-43$ \\
\hline \multirow[t]{2}{*}{ Tinnitus and $\mathrm{HL}(\mathrm{n}=68)$} & Mean & 13.69 & 32.41 & 1.74 & 43.53 & 43.93 & 11.03 \\
\hline & Range & $0-40$ & $0-96$ & $1-4$ & $25-74$ & $26-71$ & $0-38$ \\
\hline \multirow[t]{2}{*}{ Total $(n=129)$} & Mean & 12.81 & 31.44 & 1.86 & 45.26 & 45.43 & 11.78 \\
\hline & Range & $0-40$ & $0-98$ & $1-4$ & $21-74$ & $24-74$ & $0-43$ \\
\hline
\end{tabular}

HL: hearing loss, THI-S: Simplified version of Tinnitus Handicap Inventory, THI: Tinnitus Handicap Inventory, BEPSI: Brief Encounter Psychosocial Instrument, STAI: State Trait Anxiety Inventory, BDI: Beck Depression Inventory

Table 3. Distribution of patients according to severity classification

\begin{tabular}{|c|c|c|c|c|c|c|}
\hline & \multirow{2}{*}{ Group } & \multicolumn{5}{|c|}{ Severity classification (\%) } \\
\hline & & Normal & Mild & Moderate & Severe & Catastrophic \\
\hline \multirow[t]{3}{*}{ THI } & Tinnitus only & 26.23 & 44.26 & 18.03 & 9.84 & 1.64 \\
\hline & Tinnitus and $\mathrm{HL}$ & 38.24 & 29.41 & 10.29 & 14.71 & 7.35 \\
\hline & Total & 32.56 & 36.43 & 13.95 & 12.40 & 4.65 \\
\hline \multirow[t]{3}{*}{ BEPSI } & Tinnitus only & & 3.28 & 34.42 & 62.30 & \\
\hline & Tinnitus and $\mathrm{HL}$ & & 4.41 & 54.41 & 41.18 & \\
\hline & Total & & 3.88 & 44.96 & 51.16 & \\
\hline \multirow[t]{3}{*}{ STAI 1} & Tinnitus only & 67.21 & 6.56 & 16.39 & 9.84 & \\
\hline & Tinnitus and $\mathrm{HL}$ & 82.35 & 4.42 & 7.35 & 5.88 & \\
\hline & Total & 75.19 & 5.43 & 11.63 & 7.75 & \\
\hline \multirow[t]{3}{*}{ STAI 2} & Tinnitus only & 72.13 & 18.03 & 6.56 & 3.28 & \\
\hline & Tinnitus and $\mathrm{HL}$ & 76.47 & 19.12 & 1.47 & 2.94 & \\
\hline & Total & 74.42 & 18.60 & 3.88 & 3.10 & \\
\hline \multirow[t]{3}{*}{ BDI } & Tinnitus only & 37.70 & 34.43 & 18.03 & 9.84 & \\
\hline & Tinnitus and $\mathrm{HL}$ & 50 & 20.59 & 20.59 & 8.82 & \\
\hline & Total & 44.19 & 26.36 & 20.16 & 9.29 & \\
\hline
\end{tabular}

HL: hearing loss, THI: Tinnitus Handicap Inventory, BEPSI: Brief Encounter Psychosocial Instrument, STAI: State Trait Anxiety Inventory, BDI: Beck Depression Inventory 
regardless of hearing status, had moderate to severe degree of stress, as shown in BEPSI score. On average, 19\% of total participants had moderate to severe degree of anxiety in the current status as shown in STAI 1. In contrast, a relatively lower anxiety was found in the general feeling related to the tinnitus suffering (moderate to severe anxiety in $7 \%$ of total patients). Approximately $29 \%$ of total subjects showed moderate to severe degree of depression, as in distribution of BDI score.

Not surprisingly from the wide distribution of scores for both groups, results of the Mann-Whitney test showed that scores of each questionnaire did not significantly differ between tinnitus only and tinnitus and HL groups $(z=-0.48$ for THI, -0.18 for THI-S, -2.04 for STAI $1,-2.08$ for STAI 2, and -1.21 for BDI).

\section{Comparability between THI-S and THI scores}

The scatterplot (Fig. 1) visualizes the individual THI-S score according to severity classification of THI score. According to the THI classification (as displayed in different symbols in Fig. 1), forty-two subjects with no tinnitus handicap $(\mathrm{THI} \leq 16)$ had THI-S score of $0-8$. Forty-seven subjects with mild tinnitus handicap $(18 \leq \mathrm{THI} \leq 36)$ had THI-S score from 2 to 18 . Eighteen subjects with moderate tinnitus handicap $(38 \leq \mathrm{THI} \leq 56)$ had THI-S score of $14-28$. Sixteen subjects with severe tinnitus handicap $(58 \leq \mathrm{THI} \leq 76)$ had THI-S score of 20-36, and six subjects with catastrophic THI scores $(\mathrm{THI} \geq 78$ ) had THI-S score of 34-40.

As shown in Table 4, results showed that the Spearman's rank-order correlations among the total score and each subscale score for THI-S were all statistically significant, coefficients $\left(r_{s}\right)$ ranging from 0.34 to 0.84 . Since the catastrophic subscale includes only 2 items, the strength of correlation was

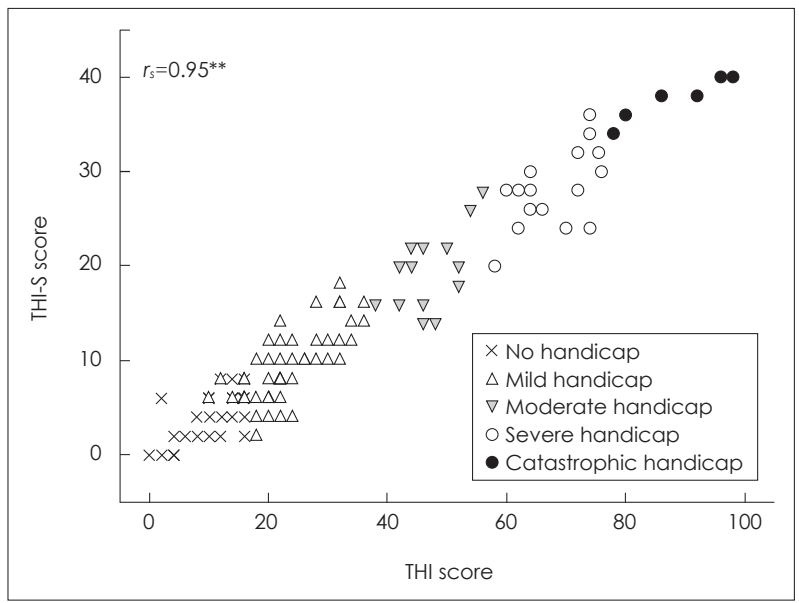

Fig. 1. Scatterplot of THI-S score according to THI score. The Spearman correlation coefficient, $r_{s}$, is shown in the figure $\left({ }^{* *} p<0.01\right)$. THI-S: Simplified version of Tinnitus Handicap Inventory, THI: Tinnitus Handicap Inventory. found to be weak to moderate. In addition, we investigated the comparability between the estimates provided by THI-S and THI questionnaires. Table 5 shows Spearman's rank-order correlations between THI-S and THI responses when comparing the scores for total and separately for each of the three subscales. As total score, there was a significant correlation between THI-S and THI responses $\left(r_{s}=0.95\right)$. Also for the scores of three subscales (functional, emotional, and catastrophic subscales), THI-S scores were positively and significantly correlated with THI scores in each subscale $\left(r_{s}=0.93\right.$ for functional subscale, $r_{s}=0.92$ for emotional subscale, $r_{s}=$ 0.85 for catastrophic subscale). This result indicates that the THI-S appears to be comparable to the original version of THI when obtaining information on self-perceived suffering from tinnitus.

\section{Usefulness of THI-S to predict tinnitus-related distress}

Since it is questionable whether THI-S is sensitive to predict tinnitus-related psychological disturbances accompanying tinnitus, the participants in this study were asked to fill in the three types of psychological measures (BEPSI, STAI, and BDI) that are widely used to evaluate stress, anxiety, and depression.

Table 6 displays Spearman's rank-order correlation coefficients $\left(r_{s}\right)$ when THI-S scores are obtained as total and each subscale scores. For the comparison purpose, the data with THI scores are also displayed in Table 6. As shown, the results indicated that the total score of THI-S was significantly and moderately correlated with BEPSI, STAI 1, STAI 2, and BDI scores $\left(r_{s}=0.40-0.45\right)$ for all participants in this tsudy. Except the catastrophic subscale which include only 2 questions, THI$\mathrm{S}$ scores in other subscales had significant relationship with BEPSI, STAI 1, STAI 2, and BDI scores $\left(r_{s}=0.37-0.47\right)$. Similar to this, the total score of THI was significantly and moderately related to BEPSI, STAI 1, STAI 2, and BDI scores $\left(0.39<r_{s}<0.46\right)$. The THI score from each subscale was also significantly related to the scores of BEPSI, STAI 1, STAI 2, and BDI scores $\left(r_{s}=0.35-0.46\right.$ for functional and emotional subscales, $r_{s}=0.19-0.28$ for catastrophic subscale). Although the strength of correlation ranged from weak to moderate, this

Table 4. Spearman's rank-order correlation among THI-S

\begin{tabular}{lccc}
\hline & $\begin{array}{c}\text { THI-S } \\
\text { total }\end{array}$ & $\begin{array}{c}\text { THI-S } \\
\text { functional }\end{array}$ & $\begin{array}{c}\text { THI-S } \\
\text { emotional }\end{array}$ \\
\hline THI-S total (10 items) & 1 & - & - \\
THI-S functional (4 items) & $0.84^{* *}$ & 1 & - \\
THI-S emotional (4 items) & $0.85^{* *}$ & $0.61^{* *}$ & 1 \\
THI-S catastrophic (2 items) & $0.64^{* *}$ & $0.34^{* *}$ & $0.40^{* *}$ \\
\hline
\end{tabular}

The Spearman correlation coefficient $\left(r_{s}\right)$ is shown in the table $(* * p<0.01)$. THI-S: Simplified version of Tinnitus Handicap Inventory 
Table 5. Spearman's rank-order correlation among THI-S and THI scores

\begin{tabular}{lcccc}
\hline & THI total (25 items) & THI functional (11 items) & THI emotional (9 items) & THI catastrophic (5 items) \\
\hline THI-S total (10 items) & $0.95^{* *}$ & $0.82^{* *}$ & $0.87^{* *}$ & $0.75^{* *}$ \\
THI-S functional (4 items) & $0.85^{* *}$ & $0.93^{* *}$ & $0.75^{* *}$ & $0.50^{* *}$ \\
THI-S emotional (4 items) & $0.83^{* *}$ & $0.63^{* *}$ & $0.92^{* *}$ & $0.57^{* *}$ \\
THI-S catastrophic ( 2 items) & $0.55^{* *}$ & $0.34^{* *}$ & $0.38^{* *}$ & $0.85^{* *}$ \\
\hline
\end{tabular}

The Spearman correlation coefficient $\left(r_{s}\right)$ is shown in the table $\left.{ }^{* *} p<0.01\right)$. THI-S: Simplified version of Tinnitus Handicap Inventory, THI: Tinnitus Handicap Inventory

Table 6. Spearman's rank-order correlation between tinnitus handicap and psychological assessment scores

\begin{tabular}{|c|c|c|c|c|}
\hline & BEPSI & STAI 1 & STAI 2 & $\mathrm{BDI}$ \\
\hline THI-S total & $0.40^{* *}$ & $0.43^{* *}$ & $0.42^{* *}$ & $0.45^{* *}$ \\
\hline THI-S functional & $0.42^{* *}$ & $0.42^{* *}$ & $0.43^{* *}$ & $0.47^{* *}$ \\
\hline THI-S emotional & $0.37^{* *}$ & $0.41^{* *}$ & $0.40^{* *}$ & $0.40^{* *}$ \\
\hline THI-S catastrophic & 0.14 & $0.18^{*}$ & 0.17 & $0.19 *$ \\
\hline THI total & $0.39 * *$ & $0.42^{* *}$ & $0.41^{* *}$ & $0.46^{* *}$ \\
\hline THI functional & $0.44^{* *}$ & $0.39 * *$ & $0.42^{* *}$ & $0.44^{* *}$ \\
\hline THI emotional & $0.35^{* *}$ & $0.42^{* *}$ & $0.40^{* *}$ & $0.46^{* *}$ \\
\hline THI catastrophic & $0.19 *$ & $0.26^{* *}$ & $0.24^{* *}$ & $0.28^{* *}$ \\
\hline
\end{tabular}

The Spearman correlation coefficient $\left(r_{s}\right)$ is shown in the table $\left({ }^{*} p<0.05,{ }^{* *} p<0.01\right)$. THI-S: Simplified version of Tinnitus Handicap Inventory, THI: Tinnitus Handicap Inventory, BEPSI: Brief Encounter Psychosocial Instrument, STAI: State Trait Anxiety Inventory, BDI: Beck Depression Inventory

Table 7. Cronbach's $\alpha$ coefficient of THI-S and THI for entire scale or each subscale

\begin{tabular}{|c|c|c|c|c|c|c|}
\hline & \multicolumn{3}{|c|}{ THI-S } & \multicolumn{3}{|c|}{$\mathrm{THI}$} \\
\hline & Tinnitus only & Tinnitus and $\mathrm{HL}$ & Total & Tinnitus only & Tinnitus and $\mathrm{HL}$ & Total \\
\hline Total & 0.83 & 0.91 & 0.88 & 0.93 & 0.95 & 0.94 \\
\hline Functional subscale & 0.75 & 0.85 & 0.81 & 0.87 & 0.89 & 0.88 \\
\hline Emotional subscale & 0.81 & 0.90 & 0.86 & 0.88 & 0.93 & 0.91 \\
\hline Catastrophic subscale & 0.78 & 0.71 & 0.76 & 0.78 & 0.83 & 0.82 \\
\hline
\end{tabular}

THI-S: Simplified version of Tinnitus Handicap Inventory, THI: Tinnitus Handicap Inventory, HL: hearing loss

indicates that tinnitus sufferers with greater tinnitus handicap would be more anxious, stressful, and depressive due possibly to tinnitus. This finding was consistent regardless whether the 10 -item THI-S or 25-item THI questionnaire was used. This supports that THI-S appears to be reliable for predicting degree of stress, anxiety, and depression of tinnitus patients.

Additional analysis was conducted to examine whether patients' age, duration, loudness, and frequency of tinnitus would be related to severity of tinnitus handicap, stress, anxiety, and depression. Any psychoacoustic feature of tinnitus such as loudness or frequency was not related to any tinnitus-relevant distress. Interestingly, the younger tinnitus listeners were found to have significantly greater stress and anxiety $\left(-0.20<r_{s}<\right.$ $-0.16)$ and greater tinnitus sufferings in the catastrophic subscale $\left(r_{s}=0.2\right)$. This indicates that the tinnitus would be more intolerable to younger listeners, resulting in a greater stress and anxiety.

Internal consistency reliability and validity of THI-S

We found that THI-S responses were highly comparable with THI responses for both tinnitus only and tinnitus and HL participants. To confirm whether the THI-S could serve as reliable to measure tinnitus handicap regardless of patients' hearing status, the internal consistency reliability of THI-S items was analyzed separately for two groups. Table 7 illustrates the Cronbach's $\alpha$ coefficients of THI-S of tinnitus only and tinnitus and HL groups, either as entire scale or each subscale. For the comparison purpose, the data with THI scores are also shown here.

When using a total score of THI-S questionnaire, the Cronbach's $\alpha$ coefficient of tinnitus only and tinnitus and HL groups was 0.83 and 0.91 , respectively ( $\alpha=0.88$ for total participants), revealing satisfactory application of THI-S to tinnitus patients for clinical and research purpose. With deleting one catastrophic item (item C8 in Table 8) among 10 items, the $\alpha$ coefficient became 0.89 for total participants, revealing not a great change. When the items of E10, E21, and E22 (Table 8) were deleted, the $\alpha$ values changed to be between $0.86-0.87$. When the reliability of THI-S was determined for each subscale, the functional and emotional subscales of THI-S revealed a good in- 
Table 8. Principal components factor analysis of the 10-item THI-S (factor loadings above 0.4 are only presented)

\begin{tabular}{|c|c|c|c|c|c|}
\hline \multirow{2}{*}{ Subscale } & \multirow{2}{*}{$\begin{array}{l}\text { Item \# } \\
\text { in THI }\end{array}$} & \multirow{2}{*}{ THI-S questions in english (THI-S questions in Korean) } & \multicolumn{3}{|c|}{ Factor } \\
\hline & & & 1 & 2 & 3 \\
\hline \multirow[t]{4}{*}{ Emotional (E) } & E10 & $\begin{array}{l}\text { Because of your tinnitus, do you feel frustrated? } \\
\text { (이명 때문에 좌절감을 느끼는 경우가 있습니까?) }\end{array}$ & 0.71 & & \\
\hline & E16 & $\begin{array}{l}\text { Does your tinnitus make you upset? } \\
\text { (이명으로 인해 기분이 몹시 상하는 경우가 있습니까?) }\end{array}$ & 0.52 & 0.55 & \\
\hline & E21 & $\begin{array}{l}\text { Because of your tinnitus, do you feel depressed? } \\
\text { (이명 때문에 우울감을 느끼십니까?) }\end{array}$ & 0.88 & & \\
\hline & E22 & $\begin{array}{l}\text { Does your tinnitus make you feel anxious? } \\
\text { (이명으로 인해 불안감을 느끼십니까?) }\end{array}$ & 0.89 & & \\
\hline \multirow[t]{4}{*}{ Functional (F) } & F1 & $\begin{array}{l}\text { Because of your tinnitus, is it difficult for you to concentrate? } \\
\text { (이명 때문에 집중하기가 어렵습니까?) }\end{array}$ & & 0.82 & \\
\hline & $\mathrm{F} 12$ & $\begin{array}{l}\text { Does your tinnitus make it difficult for you to enjoy life? } \\
\text { (이명으로 인해 삶의 즐거움이 감소됩니까?) }\end{array}$ & 0.55 & 0.55 & \\
\hline & F18 & $\begin{array}{l}\text { Do you find it difficult to focus your attention away from your tinnitus } \\
\text { and on other things? } \\
\text { (이명에서 벗어나 다른 일들에 주의를 집중하기가 어렵습니까?) }\end{array}$ & & 0.83 & \\
\hline & $\mathrm{F} 20$ & $\begin{array}{l}\text { Because of your tinnitus, do you often feel tired? } \\
\text { (이명 때문에 종종 피곤감을 느끼십니까?) }\end{array}$ & 0.46 & 0.63 & \\
\hline \multirow[t]{2}{*}{ Catastrophic (C) } & C8 & $\begin{array}{l}\text { Do you feel as though you cannot escape your tinnitus? } \\
\text { (이명에서 벗어날 수 없다고 생각하십니까?) }\end{array}$ & & & 0.9 \\
\hline & $\mathrm{C} 23$ & $\begin{array}{l}\text { Do you feel that you can no longer cope with your tinnitus? } \\
\text { (이명에 더 이상 대처할 수 없다고 생각하십니까?) }\end{array}$ & & & 0.82 \\
\hline
\end{tabular}

THI-S: Simplified version of Tinnitus Handicap Inventory, THI: Tinnitus Handicap Inventory, HL: hearing loss

ternal consistency, regardless of patients' hearing status $(\alpha=$ $0.75-0.90)$. The catastrophic subscale showed relatively lower internal consistency reliability $(\alpha=0.71-0.78)$ since it is short in length.

Like the THI-S responses, the THI questionnaire also showed good internal consistency for both tinnitus only and tinnitus and HL patients ( $\alpha$ of 0.93 and 0.95 ). Each of the three THI subscales also revealed high internal consistency $(\alpha=0.78-$ 0.93 ). Taken together, it confirms that, similar to THI responses, THI-S has a great internal consistency reliability regardless of their hearing status.

In addition, the THI-S scores were analyzed with principal components factor analysis to examine whether each subscale of THI-S comprised distinct items. The eigenvalues for the factors were 4.98 (Factor 1), 1.3 (Factor 2), and 1.1 (Factor 3 ), explaining $73 \%$ of the variance. With varimax rotation method, the factor loadings on 10 items of THI-S are displayed in Table 8 . Here, the values are only presented with loadings above 0.4 . As shown, the rotated factor loadings mostly loaded on Factor 1 and Factor 2. Among 10 items of THI-S, the 2 items of the functional subscale (F1, F18) were mainly loaded on Factor 2 whereas the 3 items of emotional subscale (E10, E21, E22) appeared to be primarily loaded on Factor 1. The 2 items of catastrophic subscale (C8, C23) were separately loaded on Factor 3 without double loadings, representing distinct variables according to the catastrophic subscale of THI-S.

\section{Discussion}

Although THI questionnaire has proved its validity and reliability internationally as a psychometrically robust measure, an interest in developing a short form of THI has grown from the need for a reliable, valid, cost-effective alternative to the original THI questionnaire. ${ }^{11)}$ The present study thus focuses upon the usefulness of the 10 -item THI-S, ${ }^{13)}$ where the three subscales of original THI were represented (4 functional, 4 emotional, 2 catastrophic items). Moreover, considering a negative impact of tinnitus on a person's psychophysical and social functioning and even life quality, we investigated whether the THI-S would be useful to predict tinnitus-related distress as well. Of 129 patients in the present study, the prevalence of depression was about $56 \%$ and state anxiety as $25 \%$. More than $50 \%$ of participants in this study had severe degree of stress. The current evidence indicates that tinnitus is often associated with anxiety and depression and especially more with stress. This is similar to the recent finding ${ }^{25)}$ that $57 \%$ and $21 \%$ of tinnitus patients $(n=104)$ showed depressive and state anxiety symptoms.

For our first research question concerning the comparability between THI-S and THI responses, the results indicated that the THI-S responses were highly comparable with THI responses $\left(r_{s}=0.85-0.95\right)$. This seems consistent with the previous findings ( $r=0.9$ ) of Mun, et al. ${ }^{13)}$ and Newman, et al. ${ }^{11)}$ It implies that reducing the number of items in THI did not affect the measurement of tinnitus handicap. Thus, THI-S 
can be used as an alternative to the original THI, especially for the screening purpose or under conditions with time constraints.

As second research question, the relation between the tinnitus annoyance and the psychological distress was determined. Although this study did not aimed to clarify cause-and-effect relationships between tinnitus handicap and general psychological symptoms, our data revealed that the severity of tinnitus was associated with psychiatric distress such as anxiety and depression of tinnitus patients. This was in agreement with numerous previous findings ${ }^{26-29)}$ that reported the negative impact of tinnitus on a person's psychological functioning and daily life and activities. The high prevalence of stress, anxiety, and depressive symptoms highlight importance of a more structured counseling plan for tinnitus patients who might be in need of psychological help. However, it is questionable whether the psychological consultation should be conducted at each patient visit for all tinnitus patients. Crocetti, et al. ${ }^{29)}$ and Cho, et al. ${ }^{25)}$ recommended the psychological counseling particularly for the patient whose THI score is greater than 38 (classified as moderate or more severity of tinnitus suffering). For THI-S responses, there is no definition to classify the tinnitus handicap severity. The cutoff value proposed by Mun, et al. ${ }^{13)}$ suggests that tinnitus patient whose THI-S score is greater than 6 would be better to have tinnitus rehabilitation therapy or other treatments. Taking into account the unbalanced and small sample size in each category of handicap, it was not possible to generate our results into precise severity classifications of THI-S as a way of grading tinnitus severity. More studies should be followed to analyze individual THI$\mathrm{S}$ responses and also grade a person's tinnitus severity.

On the basis of our results from 129 patients, we found a substantial individual variability in the severity of subjective tinnitus as well as the degree of stress, anxiety, depressive symptoms. This would be not unexpected because tinnitus is usually subjective in nature and a person's tinnitus handicap is assessed on the basis of individual self-report. In all the questionnaires used in this study, the participants fell into normal to severe degree of disabilities. Although it is known that tinnitus occurs more often in population with hearing loss than in normal-hearing population, tinnitus sufferings did not statistically differ between tinnitus patients with normal hearing and with hearing loss due to the large individual variability. Differences between individuals in their self-perceived tinnitus handicap and related distress turned out to be unpredictable with the audiologic parameters or psychoacoustical properties of tinnitus. This supports the previous finding ${ }^{4)}$ with 201 tinnitus patients that the degree of tinnitus annoyance was unrelated to the psychoacoustic features of tinnitus or other audiologic characteristics. Similarly, Park, et al. $^{30)}$ also reported that the loudness of tinnitus and other psychoacoustic characteristics of tinnitus were not strongly correlated with tinnitus-related stress, depression, and anxiety. Other previous findings also revealed a limited contribution of hearing impairment to the tinnitus-related disability. ${ }^{26,31)}$ Among various factors, only the age of tinnitus patients appeared to be greatly associated with their stress and current state of anxiety, and tinnitus suffering measured from the catastrophic subscale. In other words, the younger tinnitus patients in this study had a greater amount of stress, anxiety in their current state compared to older patients. This is in agreement with an earlier finding which showed that tinnitus patients who were younger had greater anxiety. ${ }^{30)}$ Also, younger age was found to be related to greater depressive tendency. ${ }^{32)}$ Although the current study cannot clarify the reason of this finding, younger adults might often have a hard time to manage and cope with their tinnitus for their chronological age, leading to significant psychological disturbance. Given this, appropriate psychosocial counselling should be considered depending on a patient's age or other factors such as personality, coping strategy and cognitive functioning related to attentional control.

For the third research question, the overall internal consistency of THI-S was high for total participants, as determined by Cronbach $\alpha$ of 0.88 . The moderately high consistency was also found for each of the functional, emotional, and catastrophic scales ( $\alpha$ of $0.76-0.86$ ), regardless of hearing status of patients. The confirmatory factor analysis was also conducted to examine how many factors there are and which items were loaded on which factors because this would help understand the structure of THI-S. Results demonstrated that the 3 subscales of the THI-S generally correspond to 3 different factors, but 3 items out of 10 items had double loadings. Despite the three-dimensional structure of the THI-S, some factors overlapped across different subscales. This would be determined possibly due to the original concept of THI. ${ }^{10)}$ Note that each subscale in the original THI was constructed based on the content of each item, rather than results of the factor analysis. $^{33,34)}$

Given the current findings, the THI-S was found to provide objective data of tinnitus complaints with good reliability and validity, despite having only 10 items. However, there are limitations of the present study such as no analysis of test-retest reliability and no measure of efficacy for tinnitus retraining therapy (TRT). The further longitudinal research is needed to verify whether the THI-S can reflect the reduction of disability induced by tinnitus following the TRT intervention. 


\section{Conclusion}

In this study, tinnitus handicap severity as well as relevant distress substantially varied across tinnitus patients, regardless of their hearing status. The current data of high comparability and good internal consistencies for THI-S revealed that the self-perceived suffering from tinnitus can be briefly and easily with a great reliability and validity when any constraints preclude the use of the original THI questionnaire. In addition, the THI-S responses also appeared to be a good predictor of psychological symptoms, suggesting that 10-item THI-S questionnaire can serve as a means of measuring the tinnitus handicap and its influence on a person's psychological distress reliably.

\section{REFERENCES}

1) Axelsson A, Ringdahl A. Tinnitus--a study of its prevalence and characteristics. Br J Audiol 1989;23:53-62.

2) Han W, Husain FT. Neural mechanisms and models of tinnitus generation. Audiol 2009;5:13-9.

3) Henry JA, Dennis KC, Schechter MA. General review of tinnitus: prevalence, mechanisms, effects, and management. J Speech Lang Hear Res 2005;48:1204-35.

4) Ryu SJ, Bahng J. Analysis of factors affecting tinnitus handicap inventory (THI). Audiol 2011;7:164-78

5) Lee SH, Lee JH. Effects of personal affect on tinnitus retraining therapy. Audiol 2013;9:66-73.

6) Welch D, Dawes PJ. Personality and perception of tinnitus. Ear Hear 2008;29:684-92.

7) Budd RJ, Pugh R. Tinnitus coping style and its relationship to tinnitus severity and emotional distress. J Psychosom Res 1996;41:32735 .

8) Newman CW, Wharton JA, Jacobson GP. Self-focused and somatic attention in patients with tinnitus. J Am Acad Audiol 1997;8:143-9.

9) Görtelmeyer R, Schmidt J, Suckfüll M, Jastreboff P, Gebauer A, Krüger $\mathrm{H}$, et al. Assessment of tinnitus-related impairments and disabilities using the German THI-12: sensitivity and stability of the scale over time. Int J Audiol 2011;50:523-9.

10) Newman CW, Jacobson GP, Spitzer JB. Development of the Tinnitus Handicap Inventory. Arch Otolaryngol Head Neck Surg 1996; 122:143-8.

11) Newman CW, Sandridge SA, Bolek L. Development and psychometric adequacy of the screening version of the tinnitus handicap inventory. Otol Neurotol 2008;29:276-81.

12) Bankstahl US, Elkin EP, Gebauer A, Görtelmeyer R. Validation of the THI-12 questionnaire for international use in assessing tinnitus: a multi-centre, prospective, observational study. Int J Audiol 2012;51:671-7.

13) Mun MJ, Goh EK, Oh SJ, Kwon HK, Kong SK, Lee IW. Development of simplified version of Korean-type tinnitus handicap inventory. Korean J Otorhinolaryngol-Head Neck Surg 2013;56:138-43.

14) Kim JH, Lee SY, Kim CH, Lim SL, Shin JN, Chung WH, et al. Reliability and validity of a Korean adaptation of the tinnitus handicap inventory. Korean J Otolaryngol-Head Neck Surg 2002;45:328-34.
15) Yim JH, Bae JM, Choi SS, Kim SW, Hwang HS, Huh BY. The validity of modified Korean-translated BEPSI (Brief Encounter Psychosocial Instrument) as instrument of stress measurement in outpatient clinic. J Korean Acad Fam Med 1996;17:42-9.

16) Frank SH, Zyzanski SJ. Stress in the clinical setting: the Brief Encounter Psychosocial Instrument. J Fam Pract 1988;26:533-9.

17) Bae JM, Jeong EK, Yoo TW, Huh BY, Kim CH. A quick measurement of stress in outpatient clinic setting. J Korean Acad Fam Med 1992;13:809-20.

18) Spielberger CD, Gorsuch RL, Lushene RE. Manual for the StateTrait Anxiety Inventory. Palo Alto, CA: Consulting Psychologists Press; 1970.

19) Kim JT, Shin DK. A study based on the standardization of the STAI for Korea. New Medical J 1978;21:69-75.

20) Beck AT, Steer RA. Internal consistencies of the original and revised Beck Depression Inventory. J Clin Psychol 1984;40:1365-7.

21) Han HM, Yum TH, Shin YW, Kim KH, Yoon DJ, Jung KJ. A standardization study of beck depression inventory in Korea. J Korea Neuropsychiatric Assoc 1986;25:487-502.

22) Lee YH, Song JY. A Study of the reliability and the validity of the BDI, SDS, and MMPI-D scales. J Korean Clin Psychol 1991;10:98113.

23) Rhee MK, Lee YH, Jung HY, Choi JH, Kim SH, Kim YK, et al. A standardization study of Beck Depression Inventory (II): Korean version (K-BDI): Validity. Korean J Psychopathol 1995;4:96-104.

24) Cronbach LJ. Coefficient alpha and the internal structure of tests. Psychometrika 1951;16:297-334.

25) Cho CG, Chi JH, Song JJ, Lee EK, Kim BH. Evaluation of anxiety and depressive levels in tinnitus patients. Korean J Audiol 2013;17: 83-9.

26) Zöger S, Svedlund J, Holgers KM. Psychiatric disorders in tinnitus patients without severe hearing impairment: 24 month follow-up of patients at an audiological clinic. Audiology 2001;40:133-40.

27) Robinson SK, McQuaid JR, Viirre ES, Betzig LL, Miller DL, Bailey $\mathrm{KA}$, et al. Relationship of tinnitus questionnaires to depressive symptoms, quality of well-being, and internal focus. Int Tinnitus J 2003; 9:97-103.

28) Andersson G, Westin V. Understanding tinnitus distress: introducing the concepts of moderators and mediators. Int J Audiol 2008;47 Suppl 2:S106-11.

29) Crocetti A, Forti S, Ambrosetti U, Bo LD. Questionnaires to evaluate anxiety and depressive levels in tinnitus patients. Otolaryngol Head Neck Surg 2009;140:403-5.

30) Park SN, Park DS, Park KH, Kim JH, Han MA, Yeo SW. Measurement of stress, anxiety and depression in the patients with tinnitus and their clinical significance. Korean J Audiol 2007;11:22-8.

31) Pinto PC, Sanchez TG, Tomita S. The impact of gender, age and hearing loss on tinnitus severity. Braz J Otorhinolaryngol 2010;76: $18-24$.

32) Reynolds P, Gardner D, Lee R. Tinnitus and psychological morbidity: a cross-sectional study to investigate psychological morbidity in tinnitus patients and its relationship with severity of symptoms and illness perceptions. Clin Otolaryngol Allied Sci 2004;29:628-34.

33) Zachariae R, Mirz F, Johansen LV, Andersen SE, Bjerring P, Pedersen CB. Reliability and validity of a Danish adaptation of the Tinnitus Handicap Inventory. Scand Audiol 2000;29:37-43.

34) Monzani D, Genovese E, Marrara A, Gherpelli C, Pingani L, Forghieri M, et al. Validity of the Italian adaptation of the Tinnitus Handicap Inventory; focus on quality of life and psychological distress in tinnitus-sufferers. Acta Otorhinolaryngol Ital 2008;28:126-34. 